\title{
Influence of Phosphorus on Creep Performance of DA Alloy 718
}

\author{
J. Heaney ${ }^{1}$, W. Buttrill ${ }^{1}$, J. Russell $^{2}$, and P. Mrowczynski ${ }^{3}$ \\ ${ }^{1}$ General Electric Company GE Aircraft Engines \\ One Neumann Way; Cincinnati, Ohio 45215 USA \\ ${ }^{2}$ ATI Allvac, an Allegheny Technologies Company \\ 2020 Ashcraft Avenue; Monroe, North Carolina 28110 USA \\ ${ }^{3}$ Wyman Gordon Forgings (a PCC Company) \\ 10825 Telge Road@ Hwy 290; Houston, Texas 77095
}

Keywords: Phosphorus, Creep, Alloy 718

\begin{abstract}
Achieving a balance between low cycle fatigue and creep in alloy 718 critical rotating hardware has become challenging as application conditions become more aggressive and geometries more complex. Optimization of both forge practice and of minor chemistry variations are required to meet this property balance. A review of potential factors influencing creep variation in direct age alloy 718 forgings identified phosphorus level as a statistically significant factor over the range of $50 \mathrm{ppm}$ to $125 \mathrm{ppm}$. Verification of the findings was accomplished using a series of full scale heats with phosphorus levels targeted to a $90 \mathrm{ppm}$ minimum. Data from the 12 full scale VIM heats, including 104 creep tests from multiple forgings, exhibited an average creep life of 111 hours with Q1 and Q3 distributions of 80 hours and 145 hours, respectively, when tested at $1100 \mathrm{~F} / 120$ $\mathrm{KSI}$ and $0.2 \%$ strain. This is an approximate $2 \mathrm{X}$ increase in mean life from historical levels. The results of the evaluation show that with an optimized well controlled forge process phosphorus levels above $80 \mathrm{ppm}$, but below $150 \mathrm{ppm}$, will improve creep performance of DA alloy 718 .
\end{abstract}

\section{Introduction}

In order to meet more challenging requirements being placed on gas turbines, such as longer operating lives and increased fuel efficiencies, the demands on turbine materials are increasing (increased operating temperatures, stresses, high strength and creep resistance, etc.). Achieving a balance in properties with currently available materials has been the focus of much effort. This is especially true for direct age (DA) alloy 718 where its combination of higher strength, and low cycle fatigue (LCF) capability have made it an attractive material for use in engine turbine components [1]. A typical chemistry for alloy 718 is shown in Table I.

Table I. Typical Composition for Alloy 718, Weight \%.

\begin{tabular}{|c|c|c|c|c|c|c|c|c|}
\hline $\mathrm{C}$ & $\mathrm{Cr}$ & $\mathrm{Ni}$ & $\mathrm{Fe}$ & $\mathrm{Ti}$ & $\mathrm{Al}$ & $\mathrm{Mo}$ & $\mathrm{Nb}+\mathrm{Ta}$ & $\mathrm{P}$ \\
\hline 0.025 & 17.9 & $52-54$ & $\mathrm{Bal}$. & 1.0 & 0.50 & 2.9 & 5.4 & Max. 0.0150 \\
\hline
\end{tabular}


In an effort to achieve a balance of creep and fatigue properties in a variety of DA alloy 718 components, GE, Wyman Gordon, and ATI Allvac initiated a study to evaluate the factors affecting forging creep performance. A DA alloy 718 turbine disk, forged by Wyman Gordon and used by GE in commercial jet engines, was the focus of the evaluation due to its challenging mix of requirements. The disk is forged using triple melt (VIM/ESR/VAR) alloy 718 billet. After forging, the standard alloy 718 age cycle is applied $\left(1325^{\circ} \mathrm{F} / 8\right.$ hours $+1150^{\circ} \mathrm{F} / 8$ hours $)$. Bore area test material (test ring) is used to verify part properties. Periodic creep testing $\left(1100^{\circ} \mathrm{F} / 120 \mathrm{KSI}\right)$ is required from both the rim and test ring of the forging to monitor part processing and performance. A schematic of the disk and test ring is shown in Figure 1, and typical microstructures from the disk rim and test ring areas are shown in Figure 2.

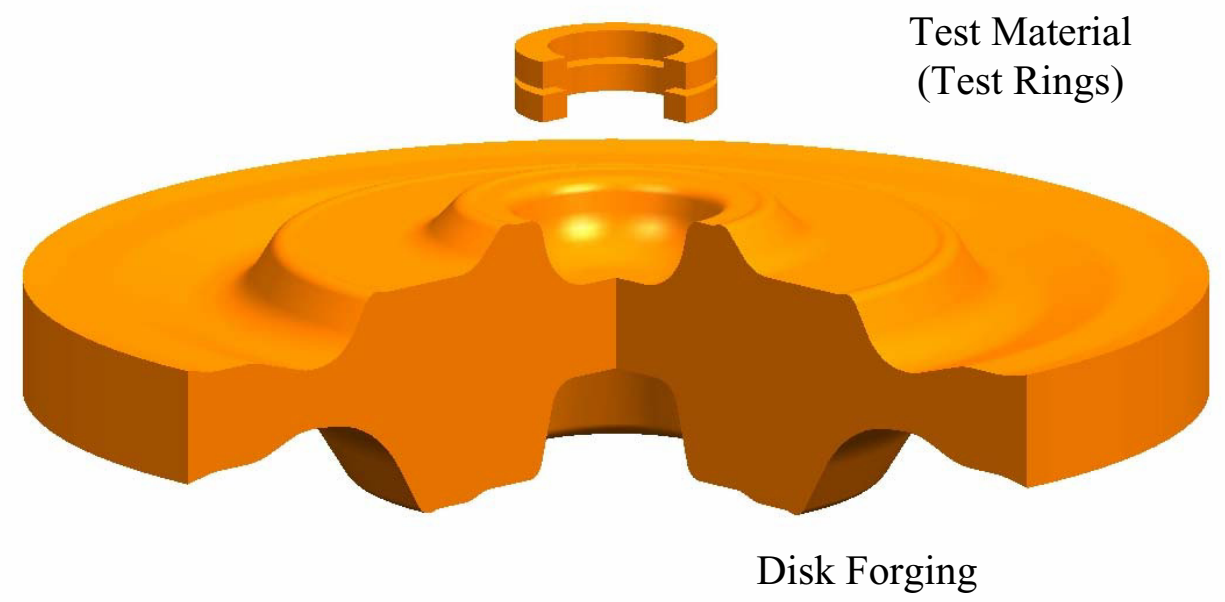

Figure 1. Turbine Disk Forging Configuration Evaluated in the Study

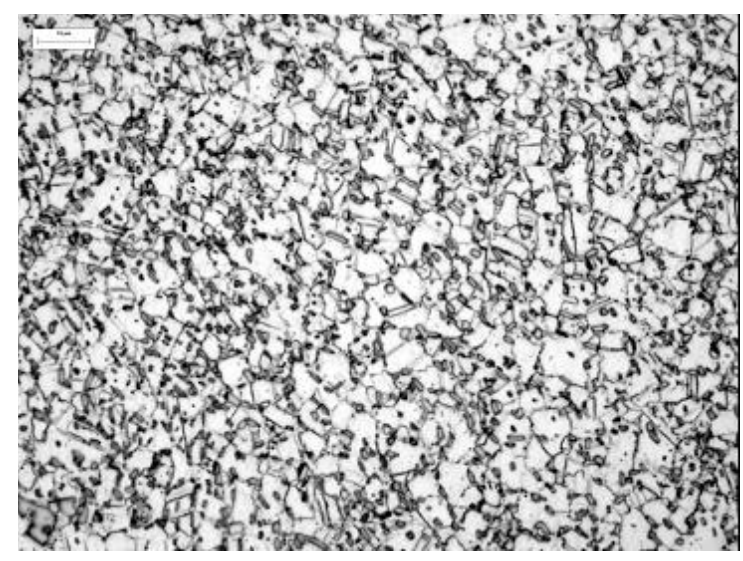

(A)

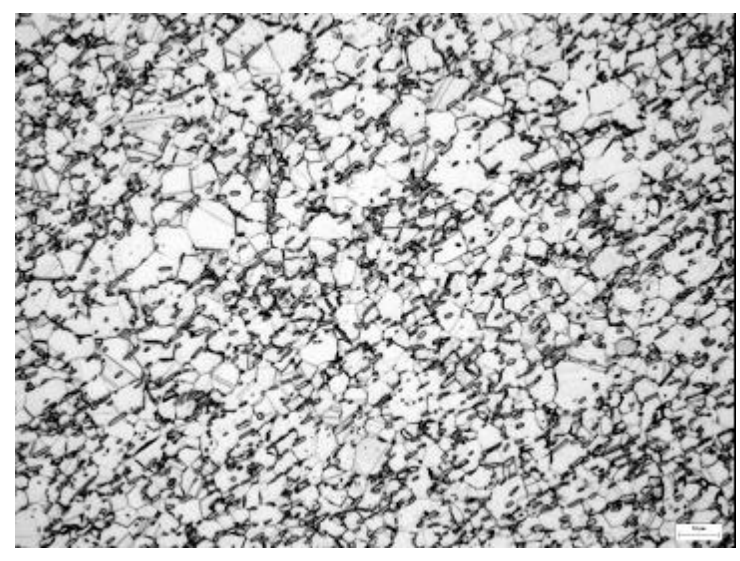

(B)

Figure 2. Typical microstructures from DA alloy 718 disk used in this study from the disk rim (A) and test ring (B). Both regions exhibit consistent fine grain structures resulting from a controlled forge practice. Micrographs are 500X magnification. 


\section{Approach}

The study was conducted in multiple phases that included an initial review of the potential sources of variation that may affect creep performance. Sources were reviewed, ranked and evaluated through statistical analysis of historical data. Chemisty variation, forge process variation, structure variation (grain size, delta phase distribution) and creep testing variation (gage R\&R) were all part of the initial review. Data from multiple turbine disks, from multiple material heats and forge runs, were used in this study. All creep testing was performed by Wyman Gordon at $1100 \mathrm{~F} / 120 \mathrm{KSI}$ with time to $0.2 \%$ strain measured.

As chemistry became the focus of the study, more detailed evaluations were performed. Thirty eight creep bars from a combination of 14 material heats and 25 forgings were selected for a combination of microstructure and chemisty evaluations. The bars were selected to cover a wide range of times to $0.2 \%$ strain ranging from 22 to 627 hours. These bars were sectioned for analyses as shown in Figure 3. GE Global Research and Development determined grain size and delta phase features (fraction, size, inter-particle spacing and aspect ratio) using EBSD (electron back scatter diffraction) SEM, and image analysis techniques. All bars were evaluated for microstructure variation while a selected sub group of 24 bars, covering all material heats, were evaluated for chemistry variation. ATI Allvac determined the test bar chemistry using x-ray fluorescence techniques.

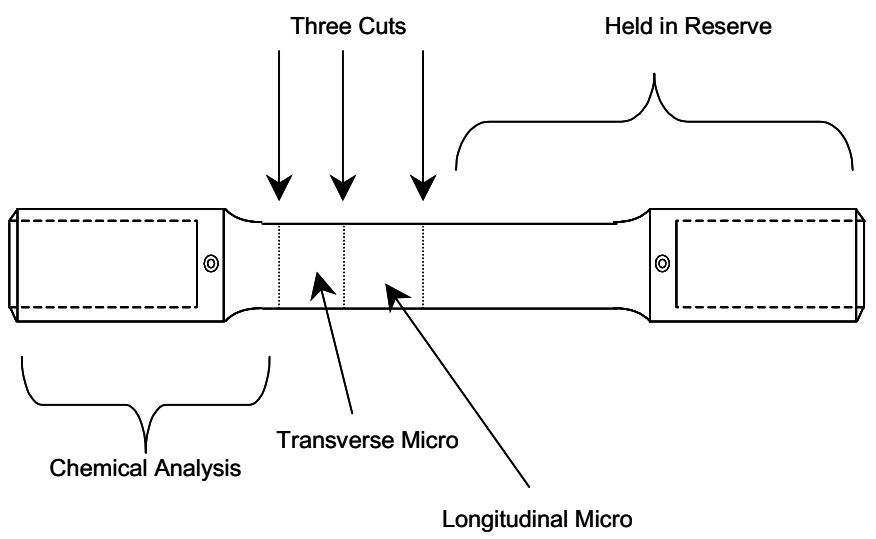

Figure 3. Creep Bar Section Plan for Microstructure and Chemistry Analysis

Finally, full scale heats of TM alloy 718 were manufactured with an aim minimum of 90 ppm $\mathrm{P}$ and applied to the production of forgings. Creep properties were measured from the test rings and rim sections of selected disks.

Evaluations of various factors and their potential influence on creep properties were performed using Analysis of Variance (ANOVA) analyses and simple liner regression of the factor against creep life (time to $0.2 \%$ creep data was transformed to log space for analysis). ANOVA analyses helped identify statistically significant differences in selected data sets using creep life (log time to $0.2 \%$ strain) as the response variable. In the ANOVA analyses the value of the parameter " $p$ " was used to discriminate factors with statistical significance. The " $p$ " value is the probability of identifying a factor as statistically significant and having that conclusion be wrong. In an analysis, factors with " $p$ " values of less than 0.05 were considered to be statistically significant. 


\section{Results}

\section{$\underline{\text { Microstructure }}$}

A summary of all data collected from the 38 samples is shown in Table II. Table II shows the averages, standard deviation and the observed range for the factors from the 38 samples. Grain size was measured using image analysis and Hein intercept techniques. A fine grain size of approximately $2.4 \mu \mathrm{m}$ (ASTM 13 to 14) was measured as shown in Table II. Measured volume fraction of delta phase was found to vary from $2.8 \%$ to $6.7 \%$ between the 38 samples. The anisotropy factor is a measure of aspect ratio variation between samples and the inter-particle spacing was measured as both a horizontal and vertical measurement from a delta phase particle in the SEM images.

Table II. Summary of Microstructure Measurements from 38 Historical Creep Specimens.

\begin{tabular}{|c|c|c|c|c|c|}
\cline { 2 - 6 } \multicolumn{1}{c|}{} & Grain Size Data & \multicolumn{4}{c|}{ Delta Phase Data } \\
\cline { 2 - 6 } \multicolumn{1}{c|}{} & Grain Size mm & $\begin{array}{c}\text { Volume } \\
\text { Fraction }\end{array}$ & $\begin{array}{c}\text { Anisotropy (1 is } \\
\text { isotropic) }\end{array}$ & $\begin{array}{c}\text { Interparticle Spacing } \\
\text { (Horiz), microns }\end{array}$ & $\begin{array}{c}\text { Interparticle Spacing } \\
\text { (Vert), microns }\end{array}$ \\
\hline Average & 2.4 & 4.8 & $0.40 \pm 0.02$ & $13.3 \pm 0.7$ & $11.1 \pm 0.6$ \\
\hline Std Deviation & 0.3 & 1 & 0.18 & 3.5 & 2.4 \\
\hline Range of Data & 1.9 to 2.9 & 2.8 to 6.7 & 0 to .84 & 6.6 to 20 & 6.5 to 15.6 \\
\hline
\end{tabular}

An ANOVA analysis of the microstructural data was performed using log time to $0.2 \%$ creep as the response variable. Sequential (factors with highest $p$ values removed between model iterations) ANOVA general linear models were used to evaluate microstructure features. A summary of the analysis is shown in Table III. The variations in grain size and delta phase volume fraction were found to not be statistically significant in the analysis as the $\mathrm{p}$ values were 0.418 and 0.764 , respectively. Inter-particle spacing and anisotropy were identified as being statistically significant, explaining about $61 \%$ of the variation in creep lives $\left(\mathrm{R}^{2}\right.$ of $61 \%$ ), however the variation in model predicted lives did not fit well with observed values and in some cases predicted negative creep lives.

Table III. Results of the General Linear Model for Microstructure Features

\begin{tabular}{|c|c|}
\hline Factor & P Value from ANOVA General Linear Model \\
\hline Grain Size & 0.418 \\
\hline Volume Fraction Delta & 0.764 \\
\hline Anisotropy Factor & 0.01 \\
\hline Inter-Particle Spacing - (Horz.) & 0 \\
\hline Inter-Particle Spacing - (Vert.) & 0.003 \\
\hline
\end{tabular}

A comparison of microstructure for long and shorter life creep samples is shown in Figure 4. While microstructure differences were noted in the ANOVA analysis, they do not appear to be significant enough to result in such a large difference in creep life. Both had similar grain size as measures by EBSD, 2.2 microns for (A) and 2.6 microns for (B) and both had similar delta phase volume fractions, 5.0 for $(\mathrm{A})$ and 3.9 for $(\mathrm{B})$. Differences in the interparticle spacing and anisotropy of the delta phases were found with sample (A) exhibiting more isotropic delta phase (0.89 vs. 0.03$)$. 


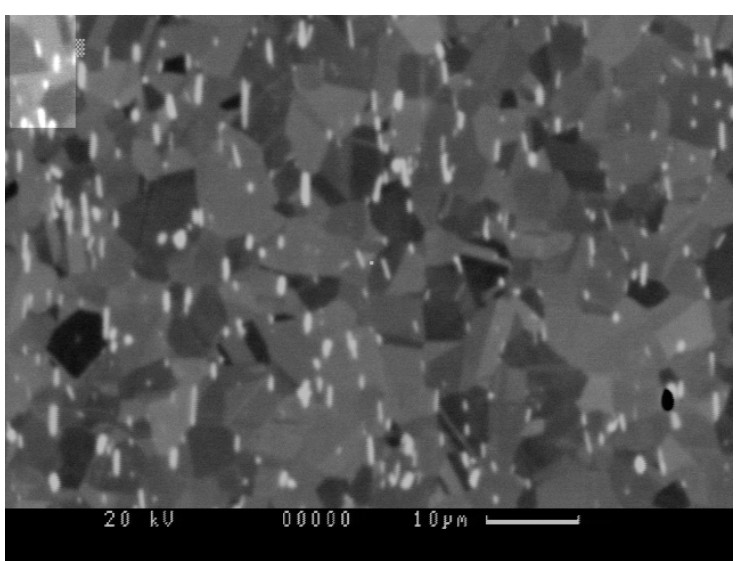

(A), 50 hours to $0.2 \%$

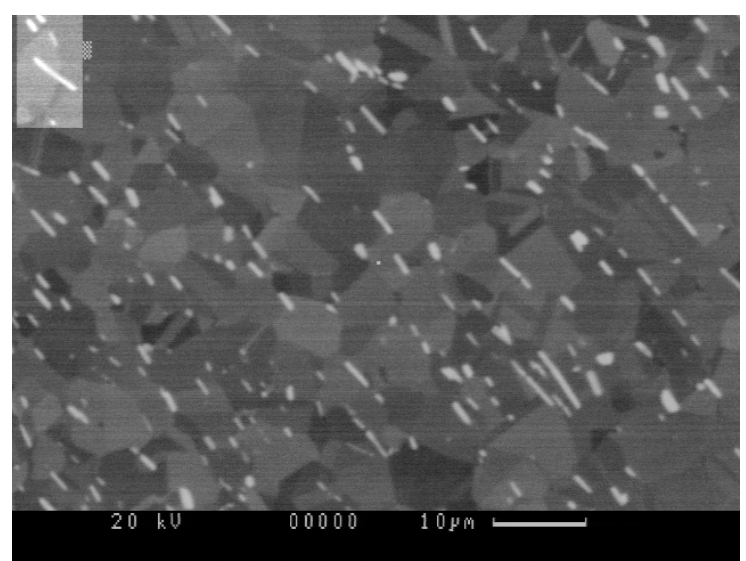

(B), 627 hours to $0.2 \%$

Figure 4. Backscatter Electron Micrographs Comparing Two Samples with Different Creep Lives.

Based on the results of the microstructure evaluations, it was concluded that variation in microstructural features alone did not explain the large difference in creep lives.

\section{$\underline{\text { Forge Process }}$}

Forge parameters that affect either the metal temperature prior to forging or the actual metal temperature during forging can result in part property variability $[2,3,4,5]$. Process variables evaluated in this study included:

1. Billet soak time prior to forging

2. Furnace thermal characteristics and differences between furnaces.

3. Transfer times between the furnace and die

4. Deformation time and strain

5. Die temperature.

Processing data from 75 production forgings was used by Wyman Gordon to evaluate the influence of these factors on the time to $0.2 \%$ creep. Analysis of the test ring creep variation was performed using ANOVA and regression techniques. Only a forge preheat furnace variation (furnace to furnace) was identified as being statistically significant early in the evaluation. Actions were taken to eliminate this as a source of variation and no other factors were identified as statistically significant.

\section{Chemistry}

Initial indications that chemistry variation may be affecting creep performance included statistically significant variation in the creep lives between multiple VIM heats observed between and within forge runs of the disk at Wyman Gordon. An initial screening showed significant heat-to-heat variability with creep life, as shown in Figure 5. This variability was also found in heats used in a single forge run, as shown in Figure 6, where heat 9 had a mean creep life of 39 hours (21 data points) and heat 10 had a mean creep life of 123 hours (12 data points). 


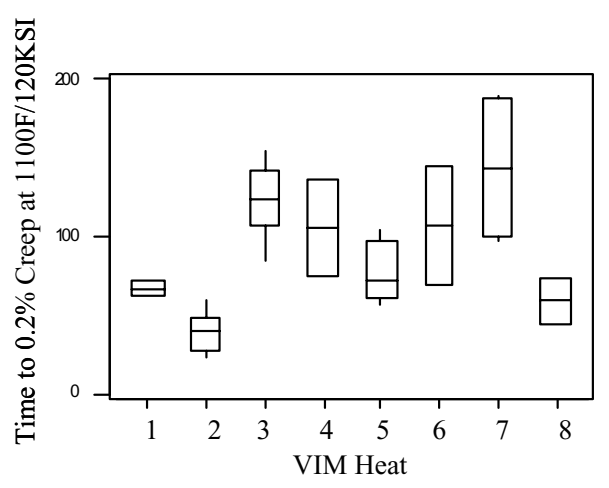

Figure 5. Variation in production test ring creep lives with material heat.

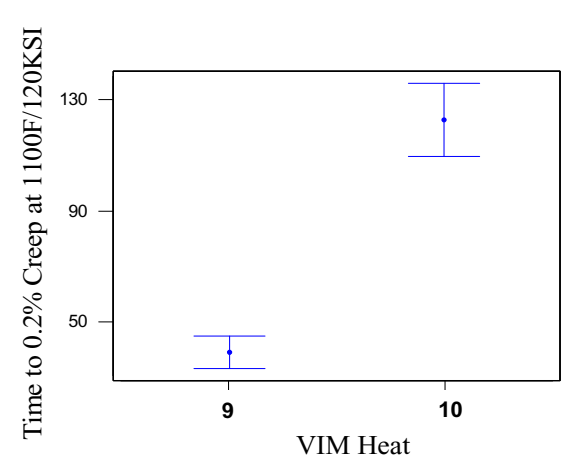

Figure 6. Example of large variation in life found between material heats forged in the same forge run.

Twenty-four creep specimens, that were part of the microstructure evaluation, were selected for chemistry measurement. A total of 14 heats were represented and the results of the creep tests are shown in Figure 7. Mean creep life was 74 hours with Q1 and Q3 quartile values of 43 and 134 hours, respectively.

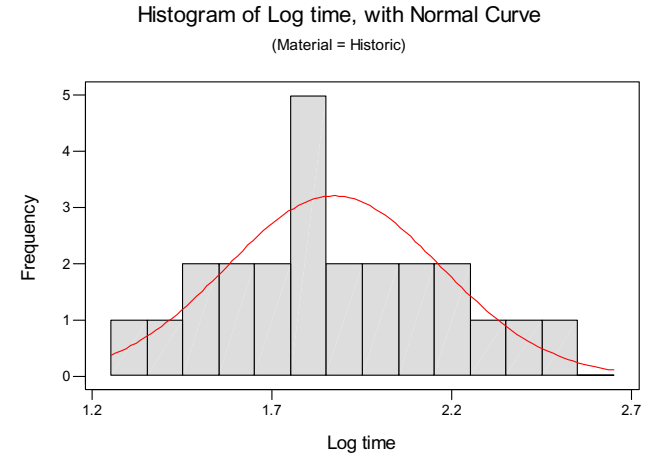

(A)
Histogram of time to $0.2 \%$ Strain

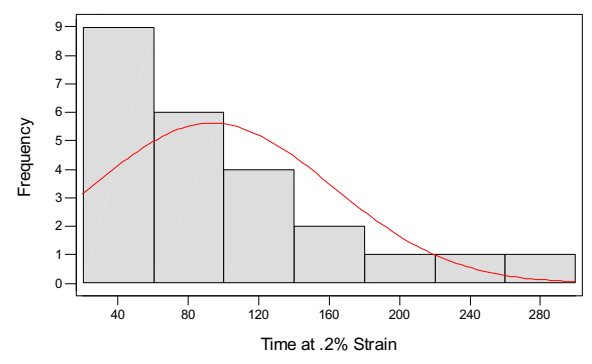

(B)

Figure 7. Results of Creep Tests from the 24 Samples Evaluated for Chemistry Effects on 1100F/120KSI Creep. Results in Log Hours (A) and Hours to 0.2\% Strain (B).

Analysis of the creep lives and chemistries from the specimens showed several elements that were statistically significant but the difference between high and low chemistry values were small and within industry gage $\mathrm{R} \& \mathrm{R}$ for the elements. Those elements were $\mathrm{Nb}, \mathrm{Cr}$, $\mathrm{Fe}, \mathrm{Ni}$ and $\mathrm{Ti}$. Elements that displayed statistically significant variation, outside the gage $\mathrm{R} \& \mathrm{R}$ range, were $\mathrm{P}, \mathrm{Mn}$ and $\mathrm{Co}$. Fitted line regression plots for $\mathrm{Co}, \mathrm{Mn}$, and $\mathrm{P}$ variation with $\log$ creep are shown in Figure 8 . The regression $\mathrm{R}^{2}$ values were $74.5 \%, 77.4 \%$ and $70.5 \%$ for $\mathrm{Co}, \mathrm{Mn}$, and $\mathrm{P}$, respectively 

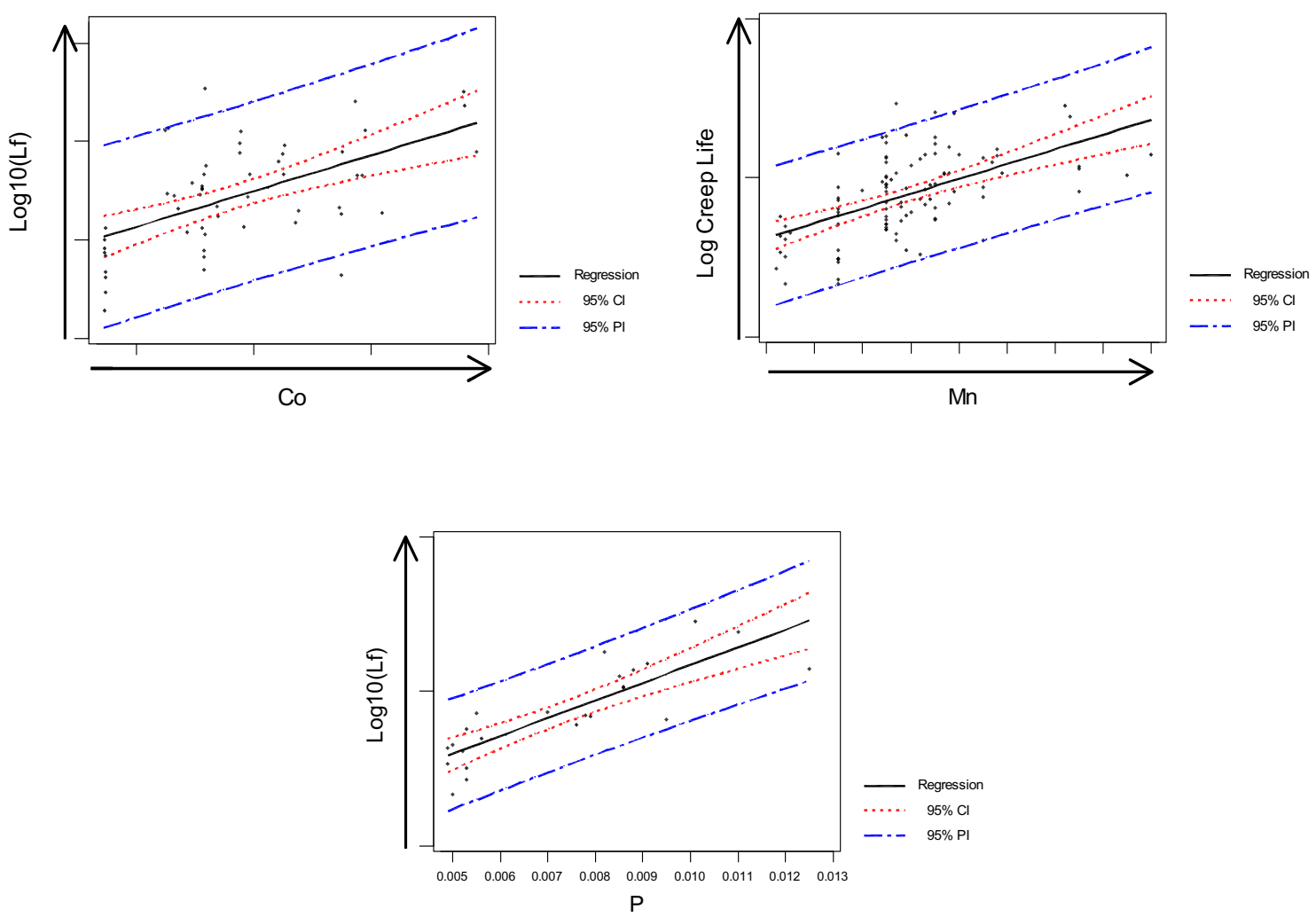

Figure 8. Results of Test Ring Chemistry Analyses Found Co, Mn, and P Variation to be Statistically Significant.

Analysis of the chemistry data also found significant correlation between $\mathrm{Co}, \mathrm{Mn}$, and $\mathrm{P}$ that confounds the interpretation of the influence of each element individually on creep. Regression analysis between the elements highlights the correlation. Fitted line regression plots for $\mathrm{P} / \mathrm{Mn}$ and $\mathrm{P} / \mathrm{Co}$ are shown in Figure 9. Note that $\mathrm{Co}, \mathrm{Mn}$, and $\mathrm{P}$ all trend in the same direction so that as $\mathrm{P}$ increases, for example, so do $\mathrm{Mn}$ and $\mathrm{Co}$.
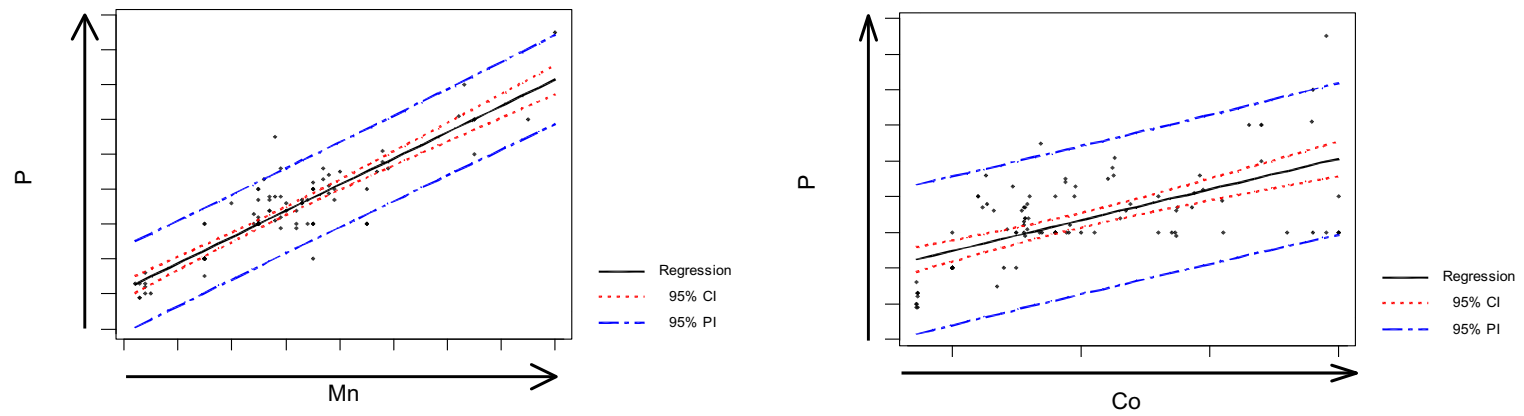

Figure 9. Significant Correlation Between Co, Mn, and P was Identified. 
Based on the results of the test ring creep analysis, the influence of $\mathrm{P}$ on creep properties was selected for further evaluation. While it was realized that confounding between Co, $\mathrm{Mn}$, and $\mathrm{P}$ does not allow determination of which element, or combination, is driving the results, process control, and metallurgical knowledge identified $\mathrm{P}$ as the element which could be controlled with the greatest potential. The test rings evaluated had $\mathrm{P}$ values ranging from 49 to $125 \mathrm{ppm}$.

\section{Confirmation Trials}

As a result of the evaluation of production heats and properties that identified $\mathrm{P}$ level as statistically significant, 12 alloy 718 heats were manufactured with a minimum P level of $90 \mathrm{ppm}$ for evaluation. ATI Allvac converted ingots to billet using approved homogenization and conversion practices and Wyman Gordon applied the billet to the manufacture of direct age forgings (Figure 1). Table IV summarizes the heats, forgings and creep tests from the confirmation trial study. Actual $\mathrm{P}$ levels measured in the final billet ranged from $90 \mathrm{ppm}$ to $110 \mathrm{ppm}$ as shown in Table IV. A total of 62 forgings were produced in 12 forge runs using production forge practices. From each forging, the test ring was removed and evaluated for grain size, creep response and tensile strength. A total of 104 creep tests were performed.

Table IV. Alloy 718 Heats, Forgings and Creep Tests Produced as Part of Confirmation Study.

\begin{tabular}{|c|c|c|c|c|}
\hline Trial Heat \# & Allvac Heat & $\mathbf{P , ~ W t \%}$ & \# Forgings & \# Creep Tests \\
\hline 1 & A & 0.011 & 5 & 10 \\
\hline 2 & B & 0.010 & 11 & 18 \\
\hline 3 & C & 0.011 & 2 & 4 \\
\hline 4 & D & 0.010 & 5 & 10 \\
\hline 5 & E & 0.009 & 8 & 16 \\
\hline 6 & F & 0.011 & 7 & 14 \\
\hline 7 & G & 0.010 & 15 & 14 \\
\hline 8 & H & 0.009 & 2 & 4 \\
\hline 9 & I & 0.009 & 2 & 4 \\
\hline 10 & J & 0.010 & 1 & 2 \\
\hline 11 & K & 0.010 & 3 & 6 \\
\hline 12 & L & 0.010 & 1 & 2 \\
\hline
\end{tabular}

Wyman Gordon performed creep testing from test rings excised from forgings made from the confirmation heats. The results of the creep tests are shown in Figure 10. Mean creep life was 111 hours and the distribution quartiles, Q1 and Q3, were 80 and 145 hours, respectively. As can be seen in Figure 11, little variation of creep life with $\mathrm{P}$ level was found over the range evaluated in the confirmation trials. 


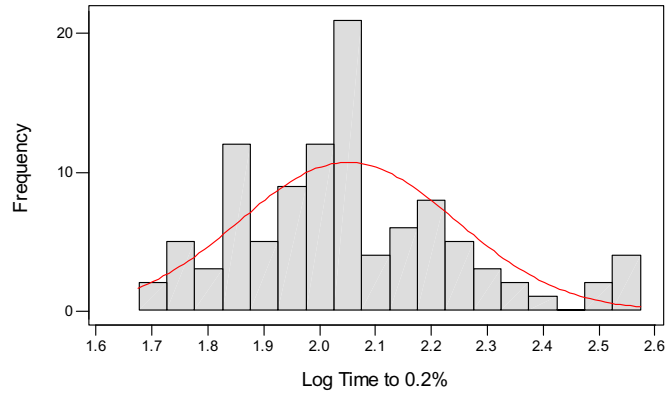

(A)

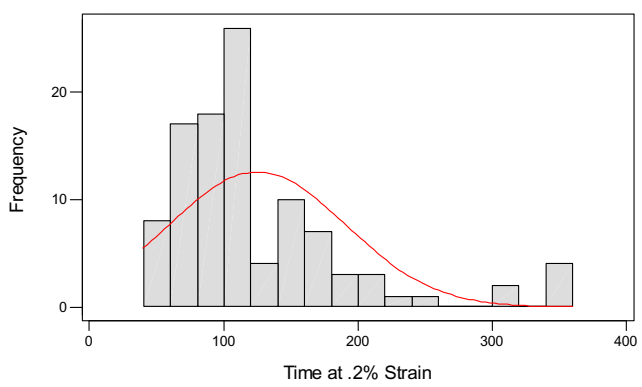

(B)

Figure 10. Results of Creep Tests Performed from Confirmation Trial Forgings. Results in Log Hours (A) and Hours to $0.2 \%$ Strain (B).

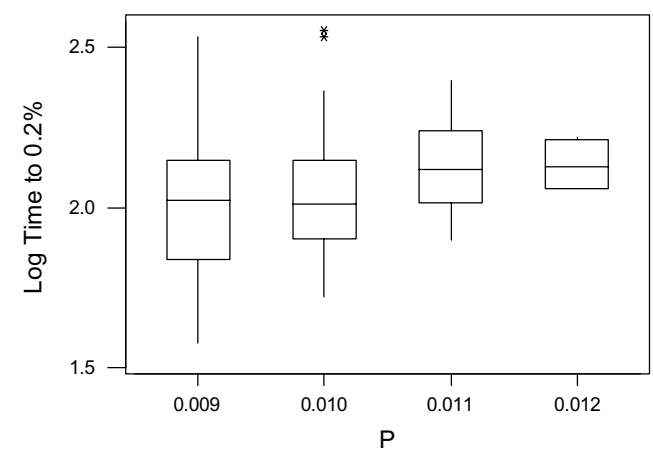

Figure 11. Boxplots Showing Creep Variation with P Level from Confirmation Trials.

\section{Discussion}

$\mathrm{P}$ contents in alloy 718 are typically in the range of $40 \mathrm{ppm}$ to $70 \mathrm{ppm}$ and in general producers tend to keep the levels well below the typical industry maximum of $150 \mathrm{ppm}$. Phosphorus ranges evaluated in this study included $\mathrm{P}$ levels higher than the typical range but are within historical experience. Occasional heats of alloy 718 are produced with $\mathrm{P}$ levels in the 100 to $110 \mathrm{ppm}$ range and a review of alloy $718 \mathrm{P}$ levels back to the mid 1980 's shows $\mathrm{P}$ levels in the range of $100 \mathrm{ppm}$ to $130 \mathrm{ppm}$ were not uncommon.

Figure 12 (A) shows the creep variation with P level evaluated in this study (historical test ring data and confirmation heats data) with a quadratic fit through the data. With a well controlled and optimized forge process, specifying a minimum level of $\mathrm{P}$ can have a beneficial effect on creep. For example, by requiring an $80 \mathrm{ppm}$ minimum $\mathrm{P}$ the average creep life could be improved from 47 hours ( $\mathrm{P}$ in the range of $50 \mathrm{ppm}$ to $80 \mathrm{ppm}$ ) to 120 hours ( $\mathrm{P}$ in the range of $80 \mathrm{ppm}$ to $125 \mathrm{ppm}$ ) with the corresponding $\mathrm{Q} 1$ and Q3 distribution quartiles improved. This is shown in Figure 12 (B) as box plots of creep life for $\mathrm{P}$ in the 50 to $80 \mathrm{ppm}$ range compared against $80 \mathrm{ppm}$ to $125 \mathrm{ppm} \mathrm{P}$. 


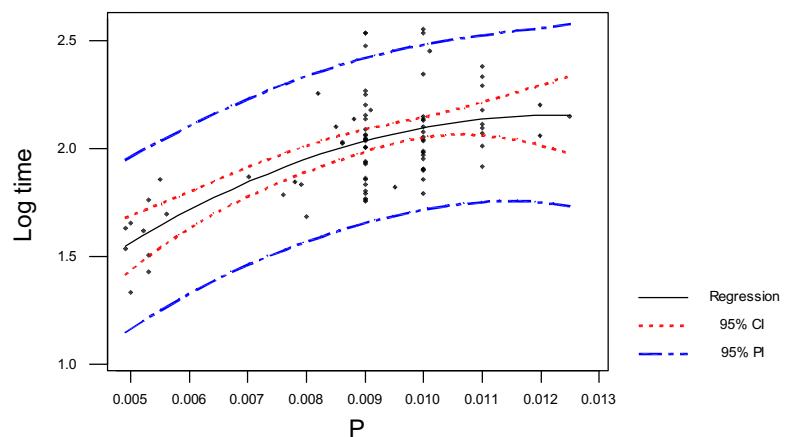

(A)

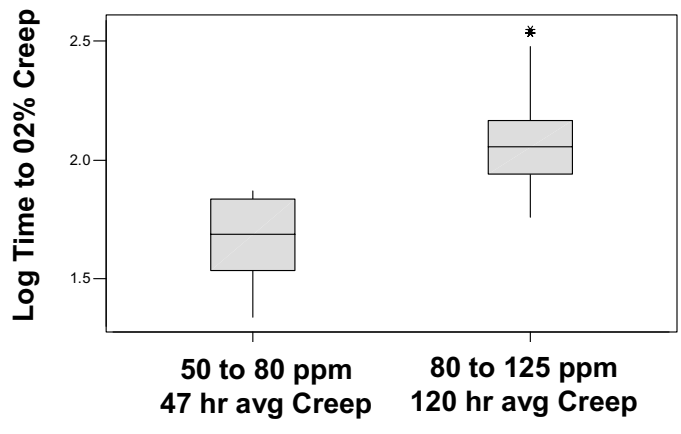

(B)

Figure 12. (A) Distribution of $\mathrm{P}$ Levels and average creep lives measured from forgings and (B) creep life distributions for the typical range of $\mathrm{P}$ in alloy 718 and for higher $\mathrm{P}$ alloy 718. An improvement in creep performance may be realized with a controlled lower limit of $\mathrm{P}$.

While the data in this study supports the beneficial impact of $\mathrm{P}$ on creep performance, the effect is not $\mathrm{P}$ alone. Creep response in forgings can be affected by many factors including selected nominal forging parameters, process variability, forging microstructure, and chemistry. When a forge process is optimized and variability reduced, higher P levels can have a beneficial affect on creep life. No amount of $\mathrm{P}$ will compensate for a nonoptimized forge process.

In addition to creep, other mechanical properties from the forgings were evaluated and no degradation identified. During this study three disk forgings from higher $\mathrm{P}$ heats $(80$ to $100 \mathrm{ppm} P$ range) were evaluated for microstructure conformance, tensile properties, low cycle fatigue properties and creep performance. The data was consistent or above historical experience for the disk and no degradation in these properties were identified. In addition, since the completion of this study multiple alloy 718 forgings have been produced and evaluated with $\mathrm{P}$ levels in the $80 \mathrm{ppm}$ to $120 \mathrm{ppm}$ range with no degradation in properties noted.

The influence of $\mathrm{P}$ on creep life observed in this study is consistent with a growing amount of data generated since the mid 1990's. Up to that time the general consensus was that $\mathrm{P}$ is a detrimental element under certain operating conditions. [6-8]. However, early work by Bieber and Decker [9] indicated P, in small amounts, was beneficial to malleability. The role of P became clearer in 1994 when Cao and Kennedy [10] demonstrated that increasing the P level of 718 up to $0.022 \%$ significantly improves stress rupture and creep properties. The improvement in stress rupture life and average creep rates exceeded an order of magnitude when $\mathrm{P}$ was raised from a few parts per million to $0.022 \%$. In this study, the $\mathrm{P}$ level was consistent with a specification limit of $0.015 \%$ maximum. The beneficial effect of increased $\mathrm{P}$ contents has been substantiated in subsequent studies by other investigations [13-16]. 
There has been some concern about the impact of higher $\mathrm{P}$ on weldability. However, investigations by Cao and colleagues [18] found no detrimental affects with increasing P. Welding and Gleeble testing by Richards and Chatuwedi [19] reported degradation in weldability that was more pronounced when $\mathrm{C}$ was very low.

At present time, many suggestions have been made regarding the mechanism of the beneficial effect of $\mathrm{P}$ in alloy 718 , but none of them has been conclusively proved. It appears that the most reasonable explanation would be the effect of $\mathrm{P}$ on grain boundary cohesion and dislocation mobility [17]. Atom probe work has demonstrated that $\mathrm{P}$ atoms in alloy 718 distribute only at two types of sites, grain boundaries and phosphorates [20]. No preferential distribution of $\mathrm{P}$ atoms at other boundaries and dislocations was found. This indicates that the effect of $\mathrm{P}$ atoms most likely come from its effect on grain boundary characteristics. It is possible that $\mathrm{P}$ atoms segregating at grain boundaries increase the grain boundary cohesion and reduce the mobility of dislocations at grain boundaries, leading to improved hot ductility and increased stress rupture and creep resistance of alloy 718 .

\section{Conclusions}

- Creep in DA alloy 718 forgings is affected by many factors including nominal forging parameters, process variability, forging microstructure, and chemistry.

- With an optimized and robust forge process phosphorus levels in the range of 80 to 125 ppm can offer the potential for improved creep performance.

- Verification trials from 62 forgings with phosphorus levels of $90 \mathrm{ppm}$ to $110 \mathrm{ppm}$ showed an approximate $2 \mathrm{X}$ increase in time to $0.2 \%$ creep for the test conditions and disk configuration used in the study.

- Mechanical properties, in addition to creep, of critical rotating parts made from TM alloy 718 with 80 to $125 \mathrm{ppm}$ phosphorus levels have also been evaluated. No detrimental effects on stress rupture notch sensitivity or ductility, tensile strength or low cycle fatigue properties were identified.

\section{References}

1. D. Krueger, "The Development of Direct Age 718 for Gas Turbine Engine Disk Applications”, Superalloy 718 - Metallurgy and Applications, 1989.

2. N. A. Wilkinson, "Forging of 718 - The Importance of TMP", Superalloy 718, Metallurgy and Applications, 1989.

3. J. Uginet, B. Pieraggi, "Study of Secondary Grain Growth on 718 Alloy", Superalloys 718, 625, 706 and Various Derivatives, 1997.

4. A. A. Guimaraes \& J. J. Jonas, "Recrystallization and Aging Effects Associated With High Temperature Deformation of Inconel 718 and Waspaloy", Met Trans A, Vol. 12A, Sept. 1981, pp 1655.

5. F. Turner, H.S. von Harrach, "Press Forging of Superalloys", Mat. Sci. \& Tech., $7 / 86$. 
6. W. Yeniscavich and C. W. Fox, in "Effect of Minor Elements on the Weldability of High Nickel Alloys", Welding Research Council, (1969), p. 24.

7. M. Tamura, in "Superalloys, Supercomposites and Superceramics", Akademic Press, Inc., 1989, p. 215.

8. D.A. Vermilyea, C.S. Tedmon, Jr., and D.E. Broecker, Corrosion, 31 (1975), p. 222.

9. C. G. Bieber and R.F. Decker, Trans AIME, 221 (1961), p. 629.

10. W.D. Cao and R.L. Kennedy, in "Superalloys 718, 625, 706 and Various Derivatives,” Ed. By E.A. Loria. TMS, (1994), p. 463.

11. X. Xie et al., Superalloys 1996, ed. R.D. Kissinger et al., (TMS 1996), 599-606.

12. X. Xie et al., Superalloys 718, 625, 706 and Various Derivatives, ed. E.A. Loria, (TMS 1997), 531-542.

13. W.R. Sun et al., Hu Metall. Trans. A, Vol. 28A, (1997), 649-654.

14. S.R. Guo et al, Superalloys 718, 625, 706 and Various Derivatives, ed. E.A. Loria, (TMS 1997), 521-530.

15. W.R. Sun et al., Mater. Sci. Eng. A, Vol. 247, (1998), 173-179.

16. X. Liu, et al., Mater. Sci. Eng. A, Vol. 270, (1999), 190-196.

17. M.K. Miller, J.A. Horton, W.D. Cao and R.L. Kennedy: "Characterization of the Effects of Boron and Phosphorus Additions to the Ni-based Superalloy 718". Presented at the 1996 International Field Emission Society meeting and published in J. De Physique, IV, C5, Vol. 6, 1996, pp. 241-246.

18. W.D. Cao and others, Internal Allvac reports.

19. N.L. Richards and M.C. Chaturvedi, "Effects of Minor Elements on Weldability of Nickel Base Superalloys", International Materials Reviews 2000 Vol. 45 No. 3 pp. 109-129.

20. S.J. Sijbrandij, M.K. Miller, J.A. Horton and W.D. Cao: "Atom Probe Analysis of Nickel-Based Superalloy IN-718 with Boron and Phosphorus Additions" Mater. Sci. Eng., A 250, 1998, pp.115-119.

\section{Acknowledgements}

The assistance of many people through out this project at GE is acknowledged including GE Global Research, (specifically Luke Brewer, Mike Larsen and Jim Grande) for microstructure analysis, Mike Lasonde for review of this manuscript, Domingo Barrera and, Fancis Visalli for design and sourcing assistance.

ATI Allvac would like to acknowledge the assistance of Dr. W.D. Cao, Larry Jackman, Jack Hyzak, Chris O’Brian, Tom Bayha, and Dick Kennedy.

Wyman-Gordon would like to acknowledge the assistance of Mark Cianci, Noshir Bhathena, Chris Harwood, Paul Hewitt, and Mike Johnson. 